\section{Funding Opportunities for Acquiring Equipment from Federal Granting Agencies}

M\&M 2004 Core Facility Management - Part III: IMR

\author{
Session Chair: Debby Sherman, Purdue University \\ dsherman@purdue.edu
}

D. Sherman: The following is a transcript of the presentation of the third speaker at the 2004 Core Facility Management session. Transcripts of the first two sections, on funding issues relating to the NSF and NIH, were published in the January and March issues of Microscopy Today. Dr. Charles Bouldin is a program director for the Instrumentation for Materials Research (IMR) program in the Division of Materials Research and also shares responsibility for the MRI awards given through the division. He is rotating into this position from his permanent position as a researcher at NIST. Charles got his $\mathrm{PhD}$ in experimental solid state Physics from U. of Washington and then has spent recent years at NIST, first in the Semiconductor Electronics Division and more recently in the Ceramics Division. His research has been primarily in $\mathrm{x}$-ray absorption, resonance $\mathrm{x}$-ray diffraction, and parallel computational applications as applied to materials research. A transcript of the question and answer session addressing all three sections will follow Dr. Bouldin's presentation.

C. Bouldin: I've been in this position now for about 3 months, so I won't give you the broad view of NSF that Angela Klaus did. Instead, I'm going to try and give a view that will be focused on what I've observed so far, and details of the programs that I help manage.

I will admit that I don't yet know what all the acronyms are. When this puzzles you I will tell you what I do. Go to Google and type in 'NSF" and then what you are interested in. That is a very quick way to find out information about a particular program. Another common mechanism, one I knew a little about before coming to NSF, is that we fund instrumentation at national user facilities such as neutron scattering centers and synchrotron radiation centers. This can be very large instrumentation or small things such as a diffractometer. Instrumentation programs that I am involved with are mostly under two million dollars. My colleague, Dr. G.$\mathrm{X}$.Tessema, is the person who administers programs seeking funding above two and less than 20 million dollars. This is something that is fairly new in that we are just ramping up this year because there was a gap in the program. We cover the small stuff fairly well, and we have efficient programs in place that cover projects above $100 \mathrm{mil}$ lion, but there was a gap for funding programs in the \$2-20 million range. This is called IMR-MIP, major instrumentation proposals. It's not a big program yet, but we are making awards.

Deadlines for the IMR-MIP program may change from last year so do check the NSF web site for current information. The deadline for the MRI program is always the third Thursday in January. We co-review MRI proposals and IMR-MIP proposals. That has some pluses and minuses in that it uses the same annual review process but it puts an enormous spike in the workload. We may adjust the things that we control so that we can distribute that workload. The IMR program has just about a $\$ 7$ million budget, MRI was funded at about $\$ 11$ million last year. The major instrumentation awards look a little inconsistent as it says 2-20 million in a 30 million dollar budget. So how does that work? These often are multi-year awards so they may actually be a million dollars for 3-4 years in a row.

The other program at NSF that didn't get mentioned is called EPSCOR, which is intended to balance programs. It's another funding mechanism to help you get funding if you live in a state that historically has not gotten a lot of federal resource funding. The way I understand it, from where you are sitting, this is probably transparent to you. You either live there or you do not. But when proposals come in and are sorted, one of the things program officers, who are always trying to get more money for their programs, do is use this to leverage programs. When you talk about things such as program balance, this is one of the mechanisms we can use to try to get a little more funding for the program we are running.

In 2004 we got 183 proposals in the IMR program and 130 in the MRI program for a total of 323 . We do what is called a mail review and each proposal gets at least 3 reviews. If we see what appears to be obvious bias than we may get another review. We then do panel reviews. We had a total of 13 panel reviews and, since we see such a diversity of requests in the Division of Materials Research, we group the reviews by instrumentation category. In addition to microscopy awards, other categories are neutron facilities, $\mathrm{X}$-ray diffractometers, beam-line instruments, and all kinds of materials deposition and fabrication equipment. We fund a lot of materials production hardware as well as characterization instruments. What come out of those three panels are 24-30 proposals, which is an indicator of the success rate. I thought you might be interested in the award amounts in these programs. In IMR, one of the smaller programs had a grant of $\$ 44,000$ and the maximum grant was just under $\$ 1$ million. This is rather unusual and was due to some special co-funding with the Office of Naval Research for that proposal.

Approximately 44 IMR awards were funded in 2004 with the mean amount of just under $\$ 250,000$. The MRI program, which is intended to be for larger awards, and is a complementary program to the IMR awards, resulted in awards from just under $\$ 100,000$ to about 2 million with a mean of about $\$ 350,000$. The way the two fit together is just the way it sounds from the data. The number of awards for MRI peaks at just about $\$ 250,000$ and the MRI picks up just about where the IMR leaves off. The over-all success for the combined programs is $25 \%$, with IMR alone accounting for about $22-23 \%$ and MRI accounting for a $26-27 \%$ success rate.

Now what is the recipe for success? Basically what you have heard before... something that is new and important, well thoughtout, and well presented. And don't forget the educational component. Preliminary results are important. Also some element of risk or uncertainty in the proposal is not only okay but expected if you are submitting a proposal that, rather than acquisitional, is developmental in nature. If you are doing a development proposal you don't know how it is going to come out. You need to indicate which parts are very doable and which parts are speculative-but that is okay.

The final critical components are the intellectual merit and broader impact of the activity.

My "from in the trenches" tips for proposals are as follows:

1. There tends to be a bit more weight given to development proposals, since this is where you get innovation, and you are not just buying a pre-existing piece of equipment. A development proposal is not buying two widgets from two different companies and putting them on the same optical table. This does not fool reviewers. 


\section{See More. Guess Less.}
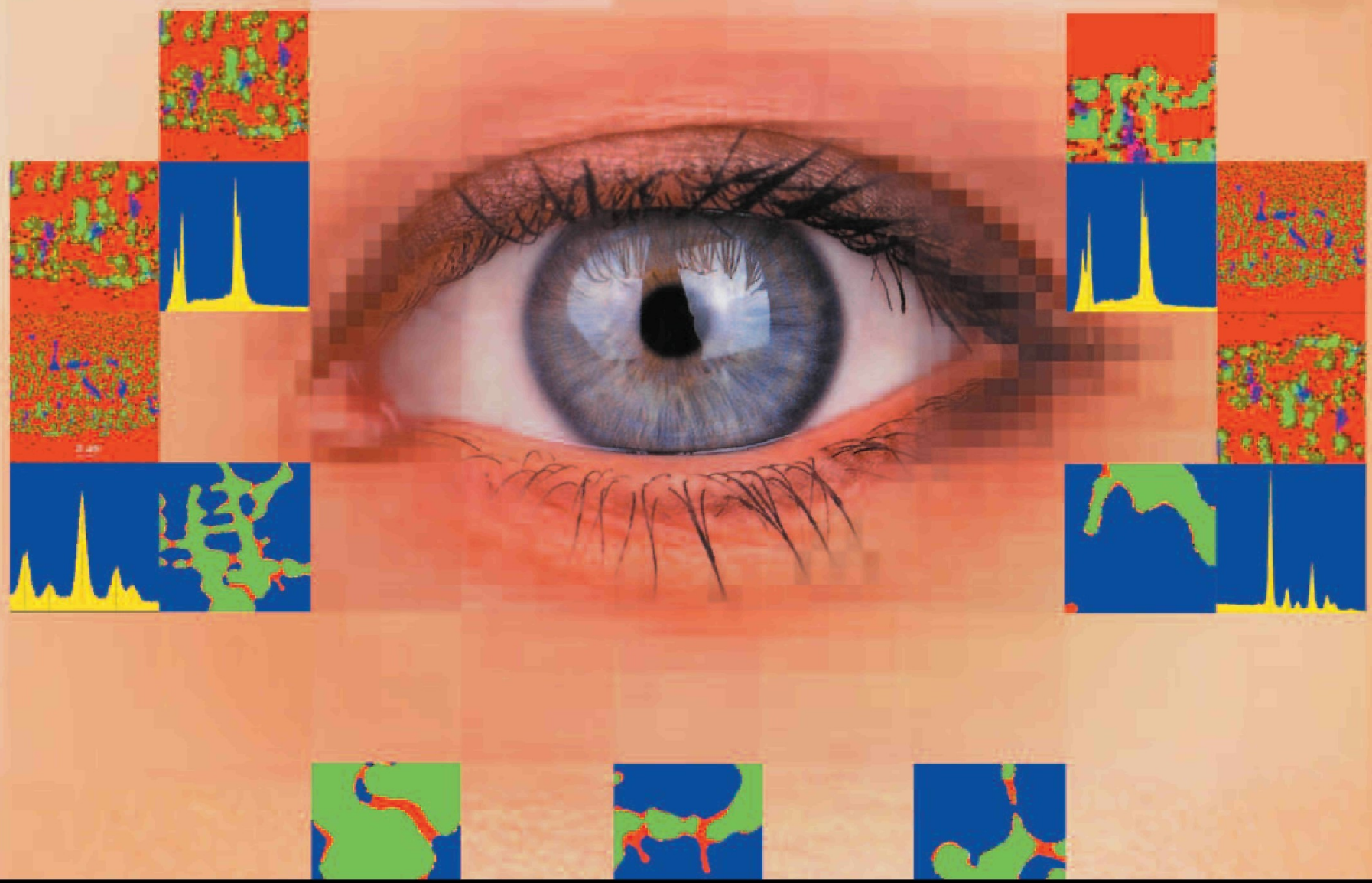

\section{NORAN System SIX for $x$-ray microanalysis}
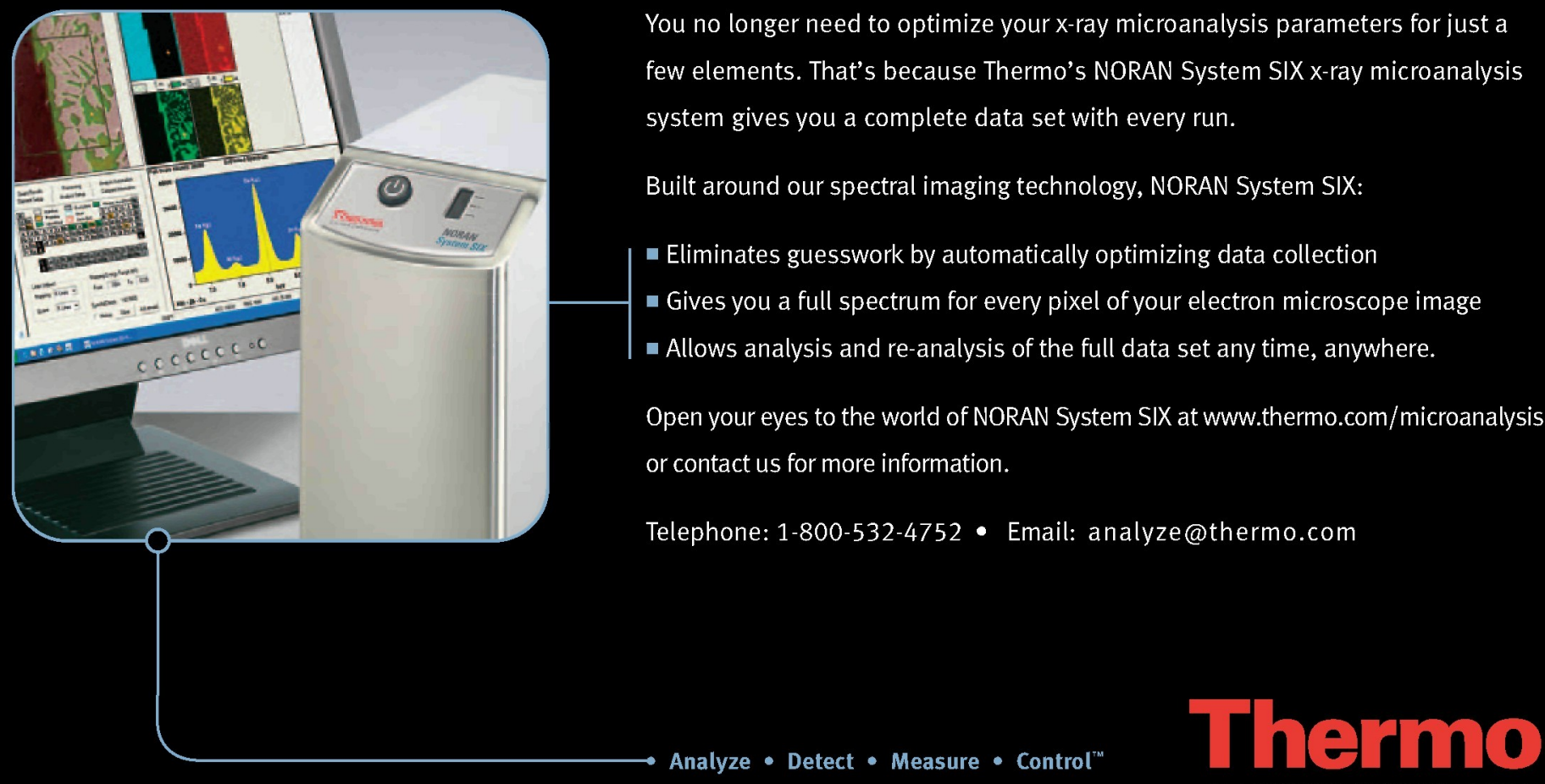
2. Since the proposals are peer reviewed, if you have an idea that you think your peers will like, than it will be a good candidate for NSF funding.

3. Don't forget the educational aspects.

4. Program officers are always looking for ways to stretch their money. Something that can be co-funded, funded across disciplines or divisions, or used for a creative addition to something you already have is always well received, as this helps stretch the dollars a bit.

5. As those before me have stressed, read the solicitation! By all means ask questions.

6. The thing that came up over and over in the panels I have observed is the cost sharing aspect. I was really impressed that there were so many proposals that we really wanted to fund but had problems that revolved around getting cost sharing redone at the last minute. Talk this over with your sponsored research office and make sure that everyone understands how that is supposed to work. As the new guy I find it confusing. Different programs have different rules with differences between acquisition and development proposals even in the same program and between $\mathrm{PhD}$ granting and non-PhD granting institutions. Also, some NSF cost-sharing requirements have been eliminated. Check the solicitation for the new rules.

To conclude, Angela said that NSF is on the way to being a paperless office. Well, let me tell you what is really happening. You submit electronically which is great. We can do declines electronically which makes it easy, but I am not sure whether this is a bug or a feature, from your standpoint. Awards are still paper because we have to have a paper trail. Thus, we go through stacks of paper during the process.

And again, we want to hear from you. I want to encourage you to contact your program officer before submitting a proposal.

\section{M\&M 2004 Core Facility Management - Part IV Questions and Answers Moderator: Debbie Sherman}

The following is a summary of questions asked by session attendees and answers provided by the speakers, Marjorie Tingle (NIH), Angela Klaus (Biological Infrastructure, NSF), and Charles Bouldin (Materials Infrastructure, NSF). If, after reading them should you have additional questions, you are encouraged to contact the respective granting agencies.

Question: There is a significant gap between the NIH shared instrumentation grant and the major instrument grants. What happens if the instrument is between the $\$ 500,000$ maximum (shared instrumentation) and $\$ 750,000$ (major instrument)?

M. Tingle: If the cost of the instrument is over $\$ 500,000$ and less than $\$ 750,000$ the application should describe the proposed source of funding for the balance of the cost of the instrument.

Question: Could you tell us a little more about the different types of institutional contribution that is required or possibly beneficial for each of the agencies?

M. Tingle: We do not have cost sharing at NIH below the maximum award. The only cost sharing is when the price of the equipment exceeds the program ceiling. In that case additional funding from the institution or other sources must be found.
A. Klaus: A recent policy change at NSF eliminated the costsharing requirements for instrumentation acquisition programs. In terms of other types of institutional commitment, support such as salaries, service contracts and long-term maintenance can strengthen your proposal. A proposal is significantly weakened if you do not have plans for long-term maintenance and training.

Question: My question for both NIH and NSF regards the attitude at your agency for the type of institutional support that comes in the form of major facility renovation or relocation expenses. Do you consider this as institutional commitment?

C. Bouldin: I cannot give a complete answer, as this would be on a case-by-case basis. There are issues of audit ability if you put in costs associates with a new building, renovation of a building or relocation to a new building. I have been told to try to make the cost share be actually for the instrument. We allow some of the other costs occasionally but not always. The reason is that auditors have found that this sometimes did not happen as promised.

A. Klaus: If renovation and/or relocation were necessary for proper installation of the instrument, a commitment by the institution to pay for these things would be an integral part of the plan for management and maintenance of the instrumentation.

M. Tingle: It's a little different in the NIH shared instrumentation program. Costs for renovation and provision of space are considered as evidence of institutional commitment to provide the infrastructure. It shows that there is an institutional track record for making technology available. However, it is not direct evidence of institutional support for the specific instrument requested. Institutional commitment is the plan for continued support for the operation and maintenance of the requested instrument in the post award period. These costs can include technician's salaries, service contracts or other costs not met by user fees. It is very important that the institution present specific financial commitments and not just moral support.

Question: You may have six PI's on an actual application generated through a major core facility but over the course of a number of years you expect to have many more major users. How much effect does this have on a review panel?

C. Bouldin: At NSF that would be addressed through the broader impacts and is something we would weight pretty heavily. The panels seem to pay a lot of attention to that as well.

A. Klaus. For an NSF proposal in that situation I would suggest you take the 6-8 strongest users of the instrumentation and describe their research projects that will utilize the equipment. You can project future usage based on utilization of current instrumentation; as Charles mentioned, this will strengthen your proposal. Additional users, major and minor, can be included in a table, or in a list with very brief research descriptions.

M. Tingle: I really tend to agree but think there are cases where more isn't better. For example, 5 or 6 users may take up all the available time on some instruments such as biosensors. Some applications have so many users that the reviewers think that there is too little time allotted for a user to get anything significant done. On the other hand if you request an instrument for a highly used core facility, such as a DNA Sequencer, then pick out your 8 best NIH funded users and have them describe their research projects. List the other minor users with their grant support. The reviewers will take all the users' needs into consideration in the overall impact 


\title{
Venture Into The Now
}

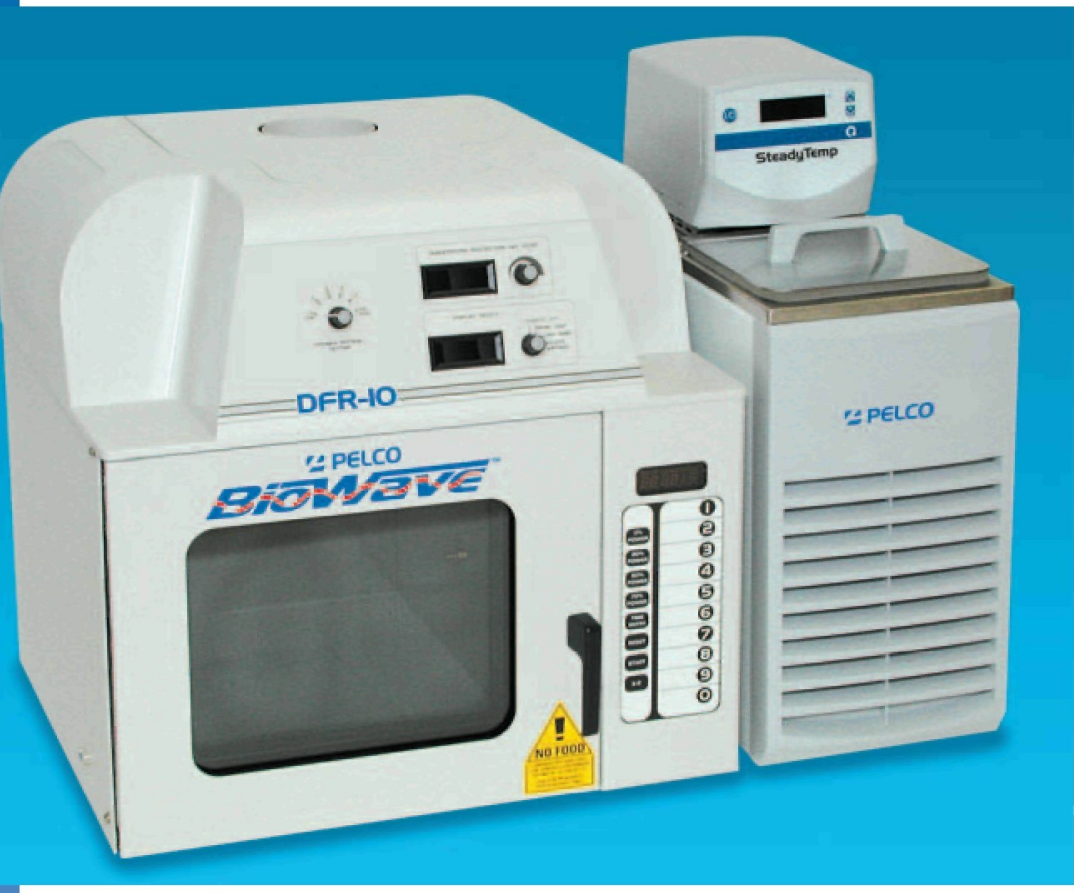

\author{
EM \& LM Processing, \\ Immunolabeling, \\ Bone Decalcification: \\ PELCO ${ }^{\circledR}$ Microwave Tissue
} Processors have more than one use
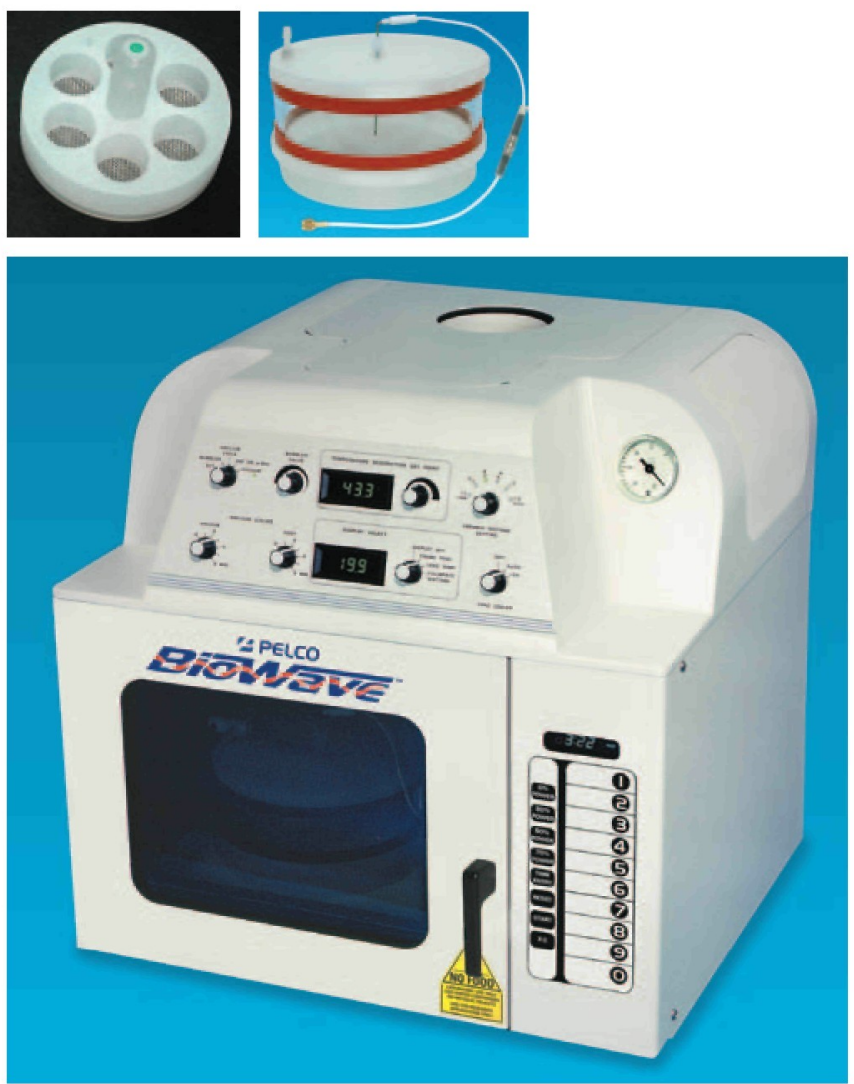

PELCO BioWave ${ }^{\circledR}$ DF-10 Laboratory Tissue Processing System

Immunology, Neurosciences, Diagnostic EM, Histology, Botany, Pharmacology and Biology are some of the fields of application. Your routine tissue processing or special investigatory trials invite methods that can improve final results and speed your work.

Variables offered by the PELCO BioWave ${ }^{\circledR}$ models, which may be adjusted to get optimum results are:

\section{Low Temperature Processing}

The only laboratory microwave system that does not rely on heating protocols but rather application of microwave energy with heat removal to optimize results.

\section{True Variable Power}

Several power levels may be selected to give $100 \%$ of that level during a time period; this means full control and constant application of power even at low wattages.

\section{PELCO ColdSpot ${ }^{\circledR}$}

A patented, effective method to hold a flat area in the processor at a certain temperature level. No hot or cold spots to "locate".

\section{Vacuum}

The 3435 PELCO ${ }^{\circledR}$ EM MW Vacuum Chamber holds vacuum down to 1 torr ( $1 \mathrm{~mm} \mathrm{Hg}, 1.33 \mathrm{mBar}$ ).

\section{Cooler than Ambient}

Our PELCO SteadyTemp ${ }^{T M}$ will permit temperature control below ambient to be run through the PELCO ColdSpot ${ }^{\circledR}$, or allow for faster fixation or decalcification.

\section{Microwave Accessories}

designed for many steps, protocols and fields.

Other operating and safety features are included.
PELCO BioWave ${ }^{\circledR}$ Laboratory Tissue Processing System
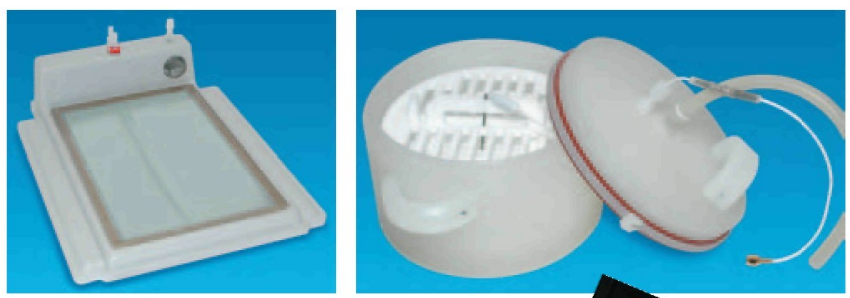

Micion

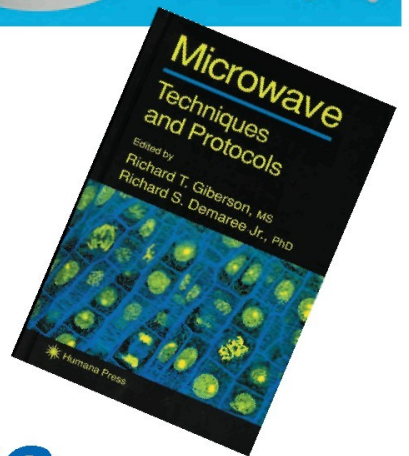

\section{TED PELLA, INC.}

Microscopy Products for Science and Industry 
to biomedical research.

Question: I am coming from a PhD granting but not a large institution in New Mexico, which is a poorer state. Now for a poorer state are the proposal guidelines different or should we emphasize the larger minority enrollment?

A. Klaus: The guidelines are not different, but if you serve a large under-represented population in an EPSCoR state, I would definitely use that as strength of your proposal. If acquiring the instrument is going to significantly impact infrastructure in the region, you should highlight that as well. That will definitely strengthen your proposal. Both of these things would be part of your discussion of broader impacts. EPSCoR stands for "Experimental Program to Stimulate Competitive Research." If a proposal from an EPSCoR state ends up on the borderline of fundability due to budgetary constraints, a program officer can go to the NSF EPSCoR office to ask for up to $50 \%$ co-funding. There are currently over 20 states and territories designated as eligible for EPSCoR funding. Details of the EPSCoR program can be found on the NSF website, and EPSCoR states also maintain their own websites.

C. Bouldin: To echo my earlier comments, if it is going to be called a development proposal then make sure it is. If you are claiming that you are from a non-PhD degree granting institution or serving an under-represented population, then put enough detail into the proposal so it doesn't sound like standard boilerplate. People are aware that there are different pathways and, since we have multiple pieces in the mission statement, there are other avenues to try to get funding. But panel reviewers have a keen sense for telling if you mean it or you don't. If you say you are going to do outreach to local high schools then you must say how in sufficient detail. It has to have enough information to show that it is a welldeveloped plan.

M. Tingle: The NIH has the Institutional Development Award program (IDeA) that is similar to the NSF EPSCORE program. You can check on the NCRR website under the Division of Research Infrastructure for more information. The IDeA grants do support instrumentation: generally small general-purpose equipment. However, for very expensive items, you will need to apply to one of the NCRR major equipment programs. If an application for shared instrumentation comes from an IDeA state and it falls just below the SIG or HEI pay line then, we will try to have the IDeA program pay that application.

Question: I come from a state that has only $2 \mathrm{PhD}$ granting universities. We would like to help the non- $\mathrm{PhD}$ granting institutions by getting support to help them come and use our facilities. Is that something that is encouraged in a proposal?

\section{Bouldin: Yes!}

A. Klaus: Certainly a sincere effort to involve primarily undergraduate institutions in your activities would be encouraged and would strengthen your proposal. However, funding support in an equipment grant to carry out these plans may not be an eligible cost. Also, if you think a non-PhD granting institution might have a good chance on their own in writing an equipment grant for the MRI program, they should be encouraged to do so. The MRI program funds are divided into separate funding streams for PhD granting and non-PhD granting institutions. The funding rates for non-PhD granting institutions have historically been high for the MRI program. Your colleagues at non-PhD granting institutions should be encouraged to call their program officer and discuss their ideas.

M. Tingle: The Biomedical Research Infrastructure Networks (BRIN) sponsored by the NCRR is intended to enhance the caliber of faculty at undergraduate institutions. I think they have an active program in your state.

Question: If we are a small facility and we have an overlap of use in materials and biological sciences, which area would proposals go to?

A. Klaus: That's a really good question. The MRI program can be a little tricky because it is designed to be able to accommodate multidisciplinary research. You submit a proposal to the Office of Integrated Activities and then you, the PI, select a Directorate or Division that you think is most appropriate for your proposal. Always go with your strengths and select the Directorate that is most appropriate for your strongest users. But then check on your proposal using Fastlane. Some proposals may be shifted within Directorates if the program directors decide they fit better in another area. For example, chemists who put in an NMR proposal to Chemistry may find that the proposal had been shifted to Biology.

Question: I manage an EM facility and have a question for Dr. Klaus. You mentioned in your presentation that one of the major funding components in the major Instrumentation program is a special congressional appropriation. Can you provide more detail about that?

A. Klaus: What I meant by that is that MRI is not a regular standing program. Charles mentioned that in Materials they have a program called IMR, which is Instrumentation for Materials Research. This is a standing program that lives permanently in DMR, the Division of Materials Research. In Biology we have a standing program called MUE, Multi-User Equipment, which lives in the Division of Biological Infrastructure permanently. The Major Research Instrumentation or MRI program is a foundation-wide activity and the money comes to NSF as a special allotment from Congress each year. In FY 2003, NSF received about 86 million dollars and in FY 2004, the amount was about $\$ 109$ million. So Congress decides how much money will go to the MRI program and the NSF Office of Integrative Activities administers the program through the Directorates.

Question: Dos that mean that our congressmen can influence the amount of funding for this program?

\section{A. Klaus: Yes.}

Question: I am from a non-PhD granting institution. However, recently they added a $\mathrm{PhD}$ in Education. Does this count?

A. Klaus: In order to be considered as a non-PhD granting institution by the MRI program, your institution must have produced fewer than 20 PhDs or SciDs in all NSF-supported fields of science, mathematics, and engineering during the previous two academic years. The Ed.D. does not count towards this definition; you are still considered a non-PhD granting institution if you meet the above requirement.

Question: Both of the NSF presentations mentioned possibilities for supplemental funding for creative additions to existing equipment and supplemental funding for previously funded grants. How long after the initial award could that be used for upgrading equipment. Does it just apply at the time of the initial purchase?

A. Klaus: I would say you would have the best chance at supplemental funding in terms of equipment is fairly close to the time of 


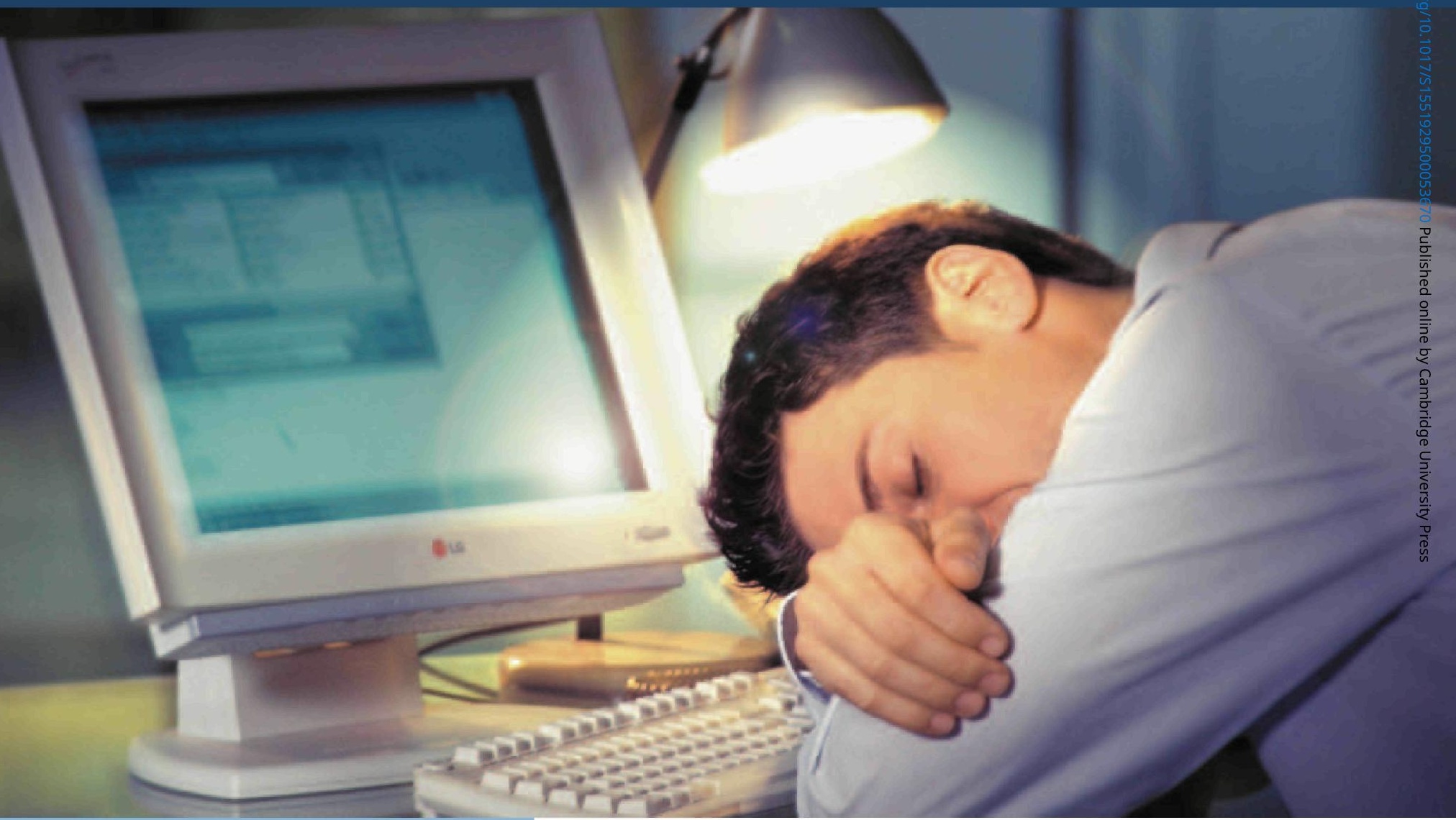

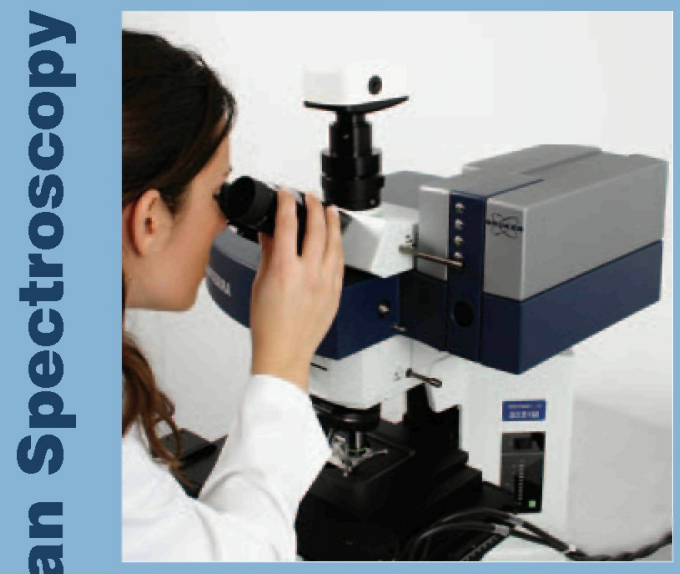

$\square$ Compact design

$\square$ Sure_Cal $I^{8}$ automated calibration

$\square$ Automatic fluorescence removal by SERDS ${ }^{\mathrm{TM}}$

$\square$ High wavelength precision of $<0.1 \mathrm{~cm}^{-1}$

$\square$ Multi laser excitation

$\square$ Confocal depth profiling

$\square$ Chemical mapping

$\square$ Real time color video

\section{Tired of spending all your time calibrating} your expensive Raman System ?

Introducing the new SENTERRA ${ }^{\text {TM }}$ affordable Dispersive Raman Microscope with patented Sure_Cal ${ }^{\circledR}$ technology

The new SENTERRA combines the sensitivity of dispersive technology and the wavelength accuracy of Fourier transform Raman spectroscopy. It provides unsurpassed performance, flexibility and ease of use by utilizing patented Sure_Cal ${ }^{\mathbb{E}}$ automatic calibration technology. The SENTERRA is a full-featured confocal system with the highest possible spatial resolution, that can accommodate multiple excitation wavelengths. It incorporates a revolutionary and patented automatic fluorescence rejection method for rejecting fluorescence from many samples.
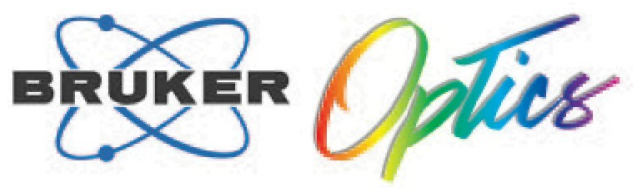

www.brukeroptics.com/microscopy 1-888-4BRUKER | microscopy@brukeroptics.com 
the award, but a request for a supplement can be submitted during the lifetime of a grant. On existing research grants, and sometimes on equipment grants, requests for supplemental funding for undergraduate researchers, high school teachers, and visiting faculty are also allowed. Always contact the appropriate program director for guidance before submitting any request for a supplement.

Question: Is there a floor for upgrades.

C. Bouldin: For IMR if the request for the supplement is more than $20 \%$ of the original award we probably will say that it should be a new proposal. For example, we would probably look fairly favorably on a request if there is a new capability that did not exist when you put in the proposal and you come back and say that for $10 \%$ more you can get significantly more capability. However, we have had some cases where awards have come in for equipment manufactured overseas. We have had supplemental requests that have to do with currency fluctuations and we don't fund them. You need to think about this initially and arrange for that contingency with your vendor beforehand.

Question: I am very interested in the NIH High-End Instrumentation program. We have a number of NIH-funded users who are very interested in cryo-EM tomography. They are presently collaborating with other folks around the country. Currently, there is no one on our campus that has this expertise. However, my university has guaranteed a hard-line position to support this proposal. I would like to know how that would play-out in the panel discussion of the proposal.

M. Tingle: In general, applications without a cryo-microscopist on board do not fare well. You need the technical expertise at the institution to develop the application and choose the appropriate instrument and accessories for the user group. There has been a general feeling among study section members that these major research instrumentation programs should not be used as recruitment tools.

A. Klaus: I think it might work a bit better at NSF. If you have even tentatively identified someone it would help. We haven't funded many of these since they are very expensive. I think if you had a critical mass of potential users and was going to build new capabilities at the institution; the panel may be supportive even if you didn't have a specialist in-hand. If you really could make a strong case for a critical mass of people who now need to take their research to the next level and they need to do cryo-EM or tomography to do that, then I think you would have a chance.

Question: I am from a strictly undergraduate research institution and we do a lot of research. We have an SEM lab but are looking to replace an SEM in the near future. Would the MRI be the program to go to in that situation?

C. Bouldin: We funded some requests very much like that this last round. MRI proposals from non-PhD granting institutions have a very high success rate.

A. Klaus: The MRI program would be very appropriate for your situation.

Question: We have a multi-user facility that includes users from biology, chemistry, engineering, and materials and so could submit to multiple NSF divisions. We have been told to list the various divisions in order. Can we really get funding from these multiple divisions for the same proposal?

A. Klaus: Chances are that it is not going to be co-funded. I think what you are describing is a priority list for which NSF Division you would prefer to review your proposal. What you put on your list as your first choice should be the Division where you can make the strongest justification for the instrumentation. You want to write a cogent and justified proposal, but you also want to excite people on the review panel. Sending a proposal to the most appropriate NSF Division will maximize the likelihood that the review panel will have people in the areas of your greatest strengths.

Question: My University is exploring setting up a multidisciplinary program in nanotechnology. We have nothing at this moment. We do have a strong relationship with some national labs and they are willing to help us. At this moment we only have 1-2 faculty on board. Is this sufficient to write a proposal for instrumentation?

C. Bouldin: I think it will be difficult to write a fundable proposal based on something that does not yet exist. However, you might need to look at this as a multi-year effort. You can submit and then take reviewers comments to improve the proposal the next time and increase your chance of funding. Persistence often ends up with a proposal being funded.

Question: I know that I can lease equipment from some companies. Can this lead to a stronger proposal for purchasing the equipment by emphasizing the need for the equipment?

M. Tingle: In my case the answer is yes. If you use the leased instrument to generate preliminary data for the major users it will definitely improve your application. However, you must be careful that the leasing agreement does not obligate you to buy the instrument. If the lease requires that you put any money down toward the purchase price it will eliminate the application from eligibility for the NIH programs.

Question: If there is existing equipment that is well proven in an area that is quite different from how you would like to apply the equipment, can you consider this new application as development?

A. Klaus: Applications or technique development is not considered instrument development.

Question: In this age of what can be done with digital magic is there a mechanism for submitting 3-dimentional images or movies with a proposal?

A. Klaus: If you want to submit a movie along with your proposal, you should contact the appropriate program officer and ask if he or she will accept the supplemental material.

M. Tingle: I would call the NIH Receipt and Referral Office to see what they consider as acceptable.

Question: Given the increase of multi-disciplinary research and core facilities, how do you deal with a proposal for equipment for a multi-disciplinary core facility as compared to a multi-disciplinary research proposal that needs an instrument? Who would review it?

A. Klaus: I dealt with this by making sure the members of the panel reflected the diversity of the proposals. The MRI program is supposed to be designed to deal with multi-disciplinary proposals from both smaller and larger institutions.

Question: I understand that it is advantageous for a proposal to have the PI be a faculty member who is one of the lead investigators in the justification for the equipment. How do panels look at non-faculty staff members who are actively involved in produc- 
tion and publication of primary research serving as co-PIs on the proposal?

A. Klaus: I don't think it would be a major concern of a review panel as long as the research is relevant to the proposed instrumentation.

M. Tingle: At NIH the PI is not required to have an active NIH grant.

Question: When you are running a core facility, your researchers are often funded by a variety of agencies such as DOE or USDA as well s NSF and NIH. In my case, we have a large agriculture school and a great deal of the funding comes from USDA. Often there are limited opportunities for major instrumentation acquisition through these agencies. Should we use those individuals as a major component of our primary group for justification or should they be buried within the secondary users of the proposed instrumentation?

A. Klaus: It depends a lot on the research. You need to determine how aligned the research is with the particular agency's mission. Choose the researchers you include in the proposal in order to best align the research with the mission and goals of the granting agency.
Question: My question concerns long-term funding of equipment maintenance. When we submit a proposal we have a plan for this funding. However, sometimes there is an unforeseen problem such as a major user leaving the university, thus, dropping anticipated revenue significantly. This is a real problem in deciding to go after high-end instrumentation for which there is a need, but also it is encumbered with a very high service contract. Are there any programs or ways to obtain temporary funds for maintaining instrumentation during an unanticipated drop in revenue to give time to regenerate needed funds?

A. Klaus: I do not think this would be possible. Requests would have to be for instrumentation, not for support.

C. Bouldin: This is an issue that is of some concern at NSF. There is not a solution or mechanism to provide this support at this time, but it certainly is being discussed.

M. Tingle: The NIH had a general research support mechanism for many years that provided funds for unanticipated resource needs. That program was terminated and no other program has been developed to provide similar sources of funding.

\section{Think \\ Nanometer-scale manufacturing requires nanometer-scale finesse}

Outside the Grid

Ascend's Xtreme Access ${ }^{\circledR}$ Incredible speed and finesse when removing TEM samples or other critical structures from nanoscale devices

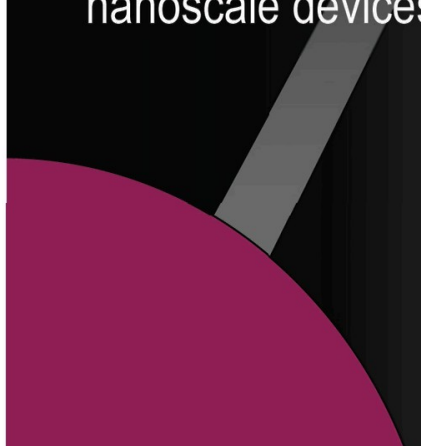

- TEM Sample Lift-out

- Molecular Manipulation

- Optical Inspection

- Voltage Contrast

- Gas Injection

- STEM Imaging

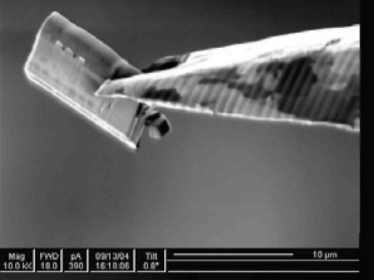

TEM sample extracted from multi-layered device without metal deposition welding

\section{Ascend Instruments}

15275 SW Koll Parkway * Beaverton * Oregon 97006 Call Toll Free:1-866-777-1940 * www.ascendinstruments.com 